\title{
The Application of Internet of Things in Metering the Consumption of Utilities in the Czech Republic
}

\author{
DOI: 10.12776/QIP.V24I1.1308 \\ Pavel Sladek, Milos Maryska, Lea Nedomova, Petr Doucek
}

Received: 2019-09-16 Accepted: 2019-11-01 Published: 2020-03-31

\begin{abstract}
Purpose: This article proposes and analyses the potential use of IoT solutions for detecting water consumption not only from technical, but also from the business and financial points of view. This topic is important because by solving this problem, companies may save a lot of money and this paper provides financial analysis, which answers question, if the implementation is or is not meaningful.
\end{abstract}

Methodology/Approach: Source data used in this paper come from an extensive survey among fifty experts from the energy supply industry in the Czech Republic during two-round workshops. One of the most attractive application has been appointed "monitoring of utility consumption" - for this article the water metering.

Findings: We have reached the conclusion that an isolated implementation of IoT technologies is much more expensive than the current solution that are based on human labour, periodical inspections of meters by people. This is caused mainly by high prices of the sonic/mechanical metering devices supporting IoT functionality.

Research Limitation/implication: Workshops and research work were realised in conditions in the Czech Republic. Principles of application opportunities and of its implementation are general, but the final decisions about their importance can be influenced by the specifics and situation in the Czech Republic.

Originality/Value of paper: The value of the paper comes from the workshops where were defined important application opportunities for definition of the priority for each of defined application opportunities.

Category: Research paper

Keywords: Internet of Things; energy industry; utility measurement; Smart City; economic evaluation 


\section{INTRODUCTION}

The potential of applications that are generally referred to as Internet of Things (IoT) has developed gradually - from its use in detecting the level of beverage cooling (Torre, Rad and Choo, 2019), to its application in systems with RadioFrequency Identification (RFID) technologies all the way to nowadays it's very important role in the world of information and communication technologies (ICT).

By the year 2013, IoT had developed into a system that combines a very big quantity of different technologies with various functions. These technologies use different communication protocols on the basis of wireless data transmission, which is an important, but also very limiting, factor. For instance, sensors, GPS and mobile equipment, devices monitoring the movement of equipment, their remote switching off or on, etc. (Al-Roubaiey et al., 2019).

IoT can be perceived as an evolution of Internet which is characterized by the integration of not only mobile devices but also other things like sensors connected to cars, home appliances, different objects into one interconnected mesh (Perera et al., 2015).

As in the other areas, we recognize various definition of IoT. The first definition of IoT is defining IoT as a dynamic global network infrastructure, with selfconfiguring capabilities based on standard and interoperable communication protocols where physical and virtual "Things" have identities, physical attributes and virtual personalities and use intelligent interfaces and are seamlessly integrated into the information system, has been generally accepted during the past two years (Van Kranenburg, 2008). The second definition, created by IEEE, defines (Minerva, Chebudie and Rotondi, 2015) Internet of Things as a: "network of objects with embedded sensors connected to the Internet. Connectivity is one of the basic pillars of IoT".

We can recognize huge amount of areas, where can be IoT used to improve quality of life and quality of provided services. One of the key areas with high added value of implementation IoT for end user (or companies) is metering of utility consumption.

Metering utility consumption with the use of IoT is an important opportunity in the "Smart Environment" area.

One of the areas of implementation of IoT technologies, which is part of the "Smart environment" concept, is their use in the production and distribution of gas, potable water and electric power - utilities in general. We have conducted a survey concerning the applicability of individual solutions in this area from a technological and economic perspective (Maryska et al., 2018). This article focuses on one application opportunity - inspection - specifically on the detection of utility consumption, which can also help to detect fraud and longterm trends for the purposes of planning sufficient production capacities. 
Electronic water meters with the function of remote reading help to reduce both non-technical water losses and the cost of physical reading of water consumption. Non-technical losses, also referred to as commercial losses, include e.g. un-metered fixed consumption, metering mistakes, billing or recording mistakes, incorrect meter installation, consumption below the sensitivity limit of water meters, water meter blocking, etc.

This concept is important for end users also. Current users prefer real-time access to information about their consumption of utilities, about situation in home (usually accessible via concept Smart home) etc. These concepts are closely related to visualization and real-time data analysis, which are another scientific topic solved in the area of IoT.

Except application areas we must mention, that application of IoT is closely connected with other negative factors, for example IoT security challenges (Jain and Singh, 2019; Nouichi et al., 2019; Moin et al., 2019), data security (SittónCandanedo, 2019), real-time data analytics (Fernández et al., 2019), energy consumption of IoT devices (Gunturi and Reddy, 2018; Liu et al., 2019), service innovation (Lee, Kao and Yang, 2014).

Mentioned solutions are part of one specific term, which is "Smart City". The Smart City has a lot of definition. According to the European Commision, a Smart City is a place, where the standard networks and services are made more efficient with the use of digital and telecommunication technologies for the benefit of its inhabitants and business. The primary goal of a Smart City is to find a concept that makes it possible for facilities to ensure sustainable growth, an excellent quality of life, safety and efficient use of energies (Lombardi et al., 2012).

\section{PROBLEM FORMULATION}

The use of IoT in this industry (Basl and Doucek, 2019) and the "Smart City" concept is very topical. One of the important applications include the monitoring of utility consumption for the purposes of automatic invoicing and fraud detection. The goal of this article is to propose and analyse the potential use of IoT solutions for detecting actual water consumption.

A similar principle can be then applied to other areas as well, e.g. the reading of energy consumption, the identification of broken seals, etc. For this reason, this is a very topical matter because by solving this problem, companies may save a lot of money. 


\section{METHODOLOGY}

The basic data identified for this article mostly come from an extensive survey among experts from the energy supply industry in the Czech Republic. The survey among 50 experts from different business companies and universities was conducted at the turn of 2016 and 2017.

To obtain relevant data, over 67 two-round workshops were conducted. The first round included 50 structured workshops, using questionnaires. Our questionnaires for asking questions and identifying technologies for IoT and business opportunities were based on the technique of guided questioning, with the use of open and closed questions (Rezanková, 2010).

Once all 50 workshops were finished, we processed and evaluated the data from the questionnaires that helped us to combine any identified duplicate application opportunities and to create a set of unique application opportunities.

In the second round of 17 workshops, experts and academicians evaluated 124 identified unique application opportunities and assigned to them priority from 1 to 3 , where 1 was the most important and 3 the least important in terms of implementation.

It is important to add that the list of identified opportunities may always change, depending on workshop participants and actual changes of information technologies in IoT.

We extrapolated the results collected from the workshops to other utility supplies where we assume a situation similar to that in the energy supply industry (Abbate et al., 2019).

\section{RESULTS}

A complete detailed overview of the results is provided and commented on in the article (Maryska et al., 2019). Using the three-level priority scale, we identified 16 application opportunities with priority 1,20 application opportunities with priority 2 and 25 application opportunities with priority 3. We identified additional 63 application opportunities but we did not assign any priority to them due to differently evaluated factors, such as importance, costs, implementation speed, societal benefits, etc.

In this article we focus on one of the application opportunities with priority 1 , specifically on "automatic reading of water consumption" that provides for many other uses, on the condition that it is done on a regular basis. 
The entire systematic solution for detecting the integrity of seals can be divided into five steps as already mentioned in the article (Doucek, Maryska and Nedomova, 2019) focused on the integrity of seals. The five identified steps are as follows:

- Technical solution;

- Sensors;

- Communication in the IoT network;

- Work with data prior to transmission;

- Power supply.

\subsection{Technical Solution - Description}

An electronic water meter is a device that contains an electronic chip that collects data about the volume of consumed water and transmits such data to the end recipient. In this case, the standard mechanical water consumption reading is not used and water consumption/through-flow is metered based on ultrasound transmission between two elements inside the electronic water meter. Identified data are electronically transmitted to the remote end recipient, or more precisely, to a cloud database where they are processed for the end recipient by the data service provider.

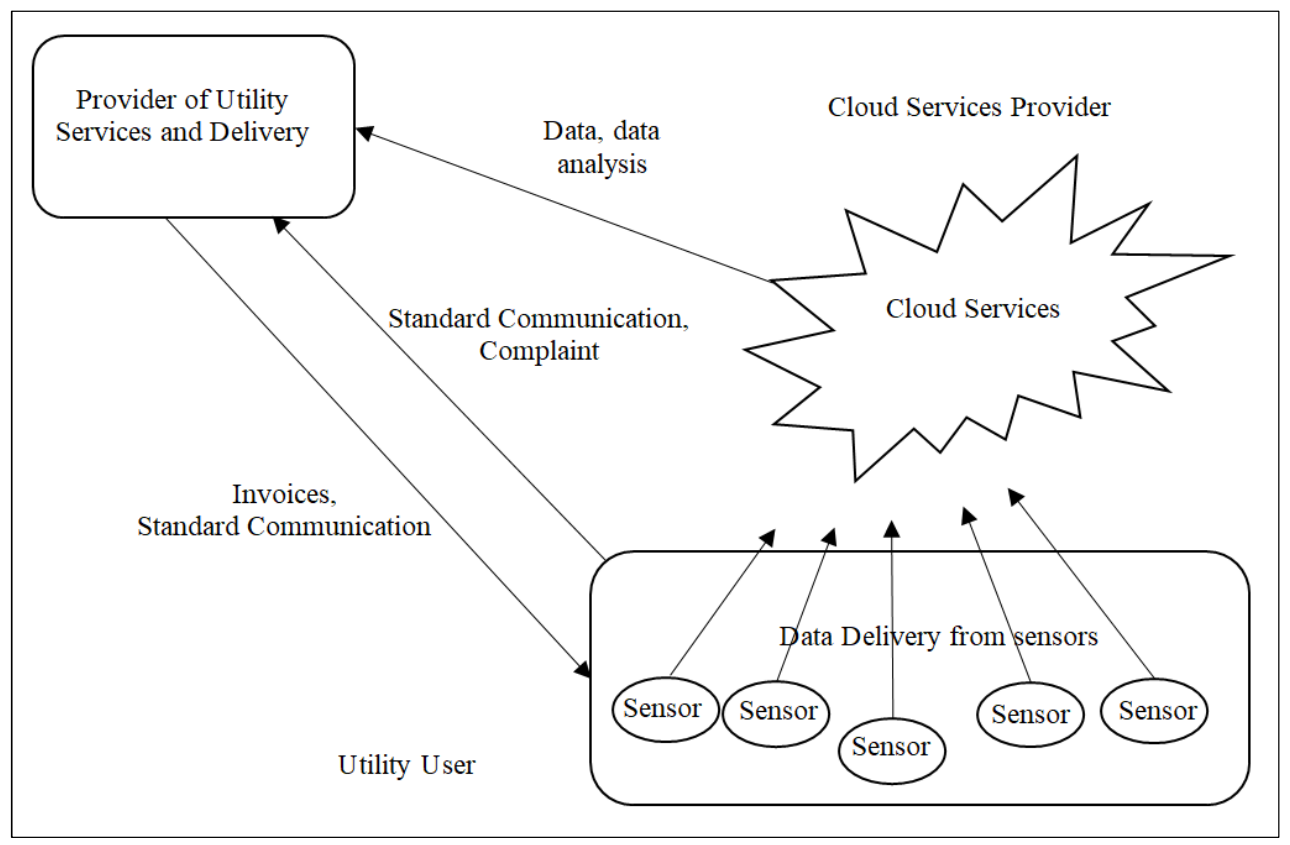

Figure 1 - Communication Concept for IoT Technology 


\subsection{Sensors}

A sensor means a general device that can be used to identify the actual consumption of utilities and to transmit information about a seal or electronic water meter that was tampered with.

It is always a single-purpose device and cannot service more than one water meter, contrary to sensors detecting broken seals.

We propose to use as a transmission IoT network NB-IoT because it is protected against interaction of devices or SIGFOX because, based on conducted tests, it is much more resistant against interference than other low-energy IoT networks. NB-IoT and SIGFOX are the only networks with sufficient all-state coverage (Kim and Kim, 2019). Interference is a key factor because one apartment can have, and usually has, several water meters. One electronic hot and cold-water meter must be placed on every ascending pipe.

What is also important about these solutions is that the device sends a message with information about battery voltage both during transmission and in idle state together with the chip temperature on a regular basis, usually every 24 hours. Another important part is the unique identification of the sensor (its ID). However, the most important information is the actual water consumption identified at the time of transmission. Every sent message is signed and encoded into a hash message by the algorithm AES128. This guarantees the integrity of the transmitted message.

In the context of the aforesaid single-purposiveness, we should say that thanks to the different method of working with identified data and thanks to installed seals for tampering validation, electronic water meters also provide other functions such as:

- Identification of cracks in the water supply network behind the user's water meter;

- Water meter tampering or blocking;

- Water supply failure/interruption e.g. due to water meter de-installation or attempted fraud;

- Reverse water flow - in this case, reverse water flow does not reduce the volume of consumed water as in the case of standard mechanical water meters.

\subsection{Communication in the IoT Network}

The device in IoT networks usually does not register in the network when sending data. The device sends the message immediately upon the data transmission request. No confirmation of message receipt is usually required in the IoT network. The robustness and guaranteed likelihood of message delivery is achieved thanks to four mechanisms that are described in detail in the article 
(Doucek, Maryska and Nedomova, 2019). The key factors are: triple transmission, a high penetration of base stations for signal reception, the use of message identifiers with incremental ID.

\subsection{Work with Data Prior to Transmission}

It is often discussed whether or not it is necessary to process the data prior to transmission. In the case of this type of message and communication, it is not necessary to pre-process the data in any major way. A defined information message is transmitted from the sensor only if the status changes or a specific event occurs, such as e.g. time or tampering with the water meter, etc.

\subsection{Power Supply}

Power supply is another important parameter of IoT solutions (Gomez et al., 2019). A battery is usually used for this type of sensor. Considering how the battery is used, its expected useful life is up to 16 years (Gomez et al., 2019). For the cost-effectiveness purposes, let's assume that its useful life is 15 years. The device is designed as low-energy because it is independent of any external source of energy to ensure that the device could not be tampered with during a power outage (Abbas and Yoon, 2015).

\section{RESULTS AND DISCUSSION}

All prices are based on market and internet research among companies developing IoT solutions and companies, which are using these IoT solutions (utilities providers).

Based on our survey among sensor manufacturers, the price of an IoT device with the function of electronic data transmission and sonic metering of water consumption and with an expected 15-year useful life is about 5,000 CZK. An alternative is a standard mechanical water meter with the function of electronic data transmission; the investment cost of the water meter with a 5-year useful life is about $600 \mathrm{CZK}$ and the investment cost of the set for remote reading with an unlimited useful life is about 2,500 CZK. In both cases, it is necessary to add installation and operating costs of the device in the IoT network. Installation costs are about $200 \mathrm{CZK}$ per device (regardless of the type of device), operating costs are about $100 \mathrm{CZK}$ per year (regardless of the type of device), the cost of device validation every five years is about $200 \mathrm{CZK}$ (only for the sonic metering option).

Assuming a 15-year useful life, total annual costs are as follows:

- In the case of sonic metering:

$5,000 \mathrm{CZK}+3 \times 200+2 \times 200+15 \times 100=7,500 \mathrm{CZK} / 15$ years

$=500 \mathrm{CZK}$ average annual operating and investment costs. 
- In the case of mechanical metering:

$3 \times 600 \mathrm{CZK}+2,500 \mathrm{CZK}+3 \times 200+15 \times 100=6,200 \mathrm{CZK} / 15$ years

$=410 \mathrm{CZK}$ average annual operating and investment costs.

When speaking of costs, we must always take into consideration benefits, proceeds or his reduction of other related costs.

When there are no technologies or no technologies are used that automatically inform the utility provider about the condition of the device, the device must be checked by a person to ensure its integrity and to identify utility consumption (water, electric power, gas).

Contrary to electrometers that are usually in hallways and thus generally accessible, water meters are always inside buildings/apartments. Therefore, it takes much longer to read/check water meters than electrometers. However, more devices can be check in one apartment since they are placed on every ascending pipe for hot and cold water.

For our analysis, it is necessary to take into account the price of a mechanical water meter with a 5-year useful life, which is on average $500 \mathrm{CZK}$, and the cost of its replacement. The installation of a new water meter costs 200 CZK. Considering the 15 -year cycle, the average annual price of a standard water meter is $3 \times 500+3 \times 200=2,100 / 15$ years $=140 \mathrm{CZK}+$ the cost of reading.

Let's assume that an average three-room apartment has three hot water meters (in the kitchen, bathroom and WC) and one cold water meter.

Let's assume that one person can check on average 30 apartments during one work shift, i.e. about 120 water meters (four apartments and 16 water meters per hour during an 8-hour work shift). It is an average value; more meters can be checked in a housing development in a big city than in a less densely populated location where it takes several or even dozens of minutes to get from one meter to another. The same applies to the number of water meters in a family home that usually has only two water meters, one cold water meter and one hot water meter.

Therefore, one person can check about 600 apartments per month, i.e. about 7,000 apartments per year. If we assume about 500,000 apartments, i.e. $2,000,000$ water meters, we will need at least 70 employees who will check and monitor the situation. Considering the average wage in Prague, which is about $40,000 \mathrm{CZK}$, it amounts to 34 million CZK in annual costs (when considering the company's costs and disregarding bonuses). To this amount, we must add the employee's cost of transportation between metering stations and the ineffective loss of his time, etc. The annual costs will be about 70 million CZK. The average annual cost of checking one apartment is about $140 \mathrm{CZK}$ for one reading, i.e. 35 CZK per water meter.

If we add the identified amount of $35 \mathrm{CZK}$ to the cost of standard water meters, we will get the average annual cost of about 175 CZK per water meter as 
compared to $410 \mathrm{CZK}$ or $500 \mathrm{CZK}$ for both options of remote electronic water meter reading.

If we assume a one-off replacement of all water meters with new sonic electronic water meters, the cost will be extreme. Investment and operating costs for 15 years will amount to approximately 15 billion CZK, which we calculated as follows: the number of apartments $\mathrm{x}$ the average number of water meters per apartment $\mathrm{x}$ average annual investment and operating costs for 15 years, i.e. about 1 billion CZK per year.

If we assume a one-off replacement of all water meters with new mechanical water meters with remote reading, investment and operating costs for 15 years will amount to approximately 12.3 billion CZK, i.e. approximately 820 million CZK per year.

If we assume a one-off replacement of all water meters with new mechanical water meters, investment and operating costs for 15 years will amount to approximately 4.2 billion CZK, i.e. approximately 280 million CZK per year. When we add another 85 million CZK for manual reading, annual costs will amount to approximately 370 million CZK, i.e. not quite $37 \%$ of the cost of electronic reading in the case of sonic meters and $45 \%$ in the case of mechanical water meters with remote reading.

This shows that a switch to either option of remote water meter reading is not currently profitable. Nevertheless, we must also take into account potential savings resulting from a timely detection of fraud, the cost of collecting the due amount or potential court fees and legal fees, etc. as well as a higher service value for customers because we can inform them about a water leak. However, it is difficult to calculate this without knowing well the data.

If we assume that the checking and reading takes place twice a year, the cost of reading goes up and the disadvantage of remote reading diminishes.

\section{CONCLUSIONS}

Based on the forecast of the Gartner Company (Panetta, 2017), we can expect a mass expansion of applications of different comprehensive "Smart City" projects that will be based on IoT technologies. These technologies can be applied in different areas of human activities, e.g. an IoT device monitoring the movement of vehicles to prevent unnecessary trips (Campero-Jurado et al., 2019), a device monitoring parking lot occupancy, a device monitoring excessive noise and many others (Jia et al., 2019).

In this article, we focused on one specific application opportunity, which is the use of IoT sensors monitoring utility consumption (water, gas, electric power as well as the volume of transmitted data). In our case, it is the application for monitoring water consumption with the use of water meters based on IoT technologies. End customers have water meters allowing on-line reading of water 
consumption. It also makes it possible to detect any potential attempt to illegally tamper with water consumption, such as water meter blocking, reverse water flow, etc.

The main benefits of these solutions are as follows:

- Immediate identification of tampering with a water meter;

- Online information about actual consumption;

- Easy installation;

- Additional services, such as information about the risk of a water leak, etc.

Negative factors include the limited useful life of the device, which is usually 15 years. This disadvantage is however compensated by the fact that e.g. mechanical water meters are replaced once every five years. Gas meters and electrometers are replaced about this often as well.

The current cost of implementation of the innovative solutions is another negative factor. The calculations in this article clearly show that the solutions are modern but the cost of their implementation currently hinders their mass expansion.

The volume of radio communications mainly in densely populated locations represents another risk factor because it could interfere with the signal transmitted from water meters and even with the entire network. Potential interference could be also caused by bad weather - heavy rain, fog (Venticinque and Amato, 2019) or snow.

Identified results are highly dependent on current market prices, nevertheless importance of this analysis is emphasise by the fact, that Metering the Consumption of Utilities was identified by Czech citizens as top priority of IoT implementation.

Our results are confirms, that before any decision the proper economic analysis (for example cost benefit analysis) has to be done. This analysis should show that not all IoT technology models are cost effective.

\section{ACKNOWLEDGEMENTS}

Paper was processed with contribution of long-term support of scientific work on Faculty of Informatics and Statistics, University of Economics, Prague (IP 400040). 


\section{REFERENCES}

Abbas, Z. and Wonyong, Y., 2015. A Survey on Energy Conserving Mechanisms for the Internet of Things: Wireless Networking Aspects. Sensors, [e-journal] 15(10), pp.24818-24847. DOI: 10.3390/s151024818.

Abbate, T., Cesaroni, F., Cinici, M.C. and Villari, M., 2019. Business models for developing smart cities. A fuzzy set qualitative comparative analysis of an IoT platform. Technological Forecasting and Social Change, [e-journal] 142(C), pp.183-193. DOI: 10.1016/j.techfore.2018.07.031.

Al-Roubaiey, A., Sheltami, T., Mahmoud, A. and Yasar, A., 2019. EATDDS: Energy-aware middleware for wireless sensor and actuator networks. Future Generation Computer Systems-the International Journal of Escience, [ejournal] 96, pp.196-206. DOI: 10.1016/j.future.2019.01.060.

Basl, J. and Doucek, P., 2019. A Metamodel for Evaluating Enterprise Readiness in the Context of Industry 4.0. Information, [e-journal] 10(89), pp.1-13. DOI: 10.3390/info10030089.

Campero-Jurado, I., Quintanar-Gomez, J., Vargas-Buitron, O.D., TrejoMacotela, F.R., Robles-Camarillo, D. and Simancas-Acevedo, E., 2019. Embedded system based on IoT and V2X for Smart Cities. International Journal of Combinatorial Optimization Problems and Informatic, 10(3), pp.50-58.

Doucek, P., Maryska, M. and Nedomova, L., 2019. The Application of IoT in the Area of Detection. In: University of Hradec Králové, Hradec Economic Days, International Scientific Conference. Hradec Králové, Czech Republic, 05-06 February 2019. Hradec Králové: University of Hradec Králové. pp.128-134.

Fernández, A.M., Gutiérrez-Avilés, D., Troncoso, A. and Martínez-Álvarez, F., 2019. Real-Time Big Data Analytics in Smart Cities from LoRa-Based IoT Networks. In: F.M. Álvarez, A.T. Lora, J.A.S. Munoz, H. Quintián and E. Corchado, 14th International Conference on Soft Computing Models in Industrial and Environmental Applications (SOCO 2019). Seville, Spain, 13-15 May 2019. Springer, Cham. pp.91-100.

Gomez, C., Veras, J.C., Vidal, R., Casals, L. and Paradells, J., 2019. A Sigfox Energy Consumption Model. Sensors, [e-journal] 19(3), 20p. DOI: 10.3390/s19030681.

Gunturi, Sri Krishna Sankalp and M. Sai Krishna Reddy. 2018. IoT Based Domestic Energy Monitoring Device. In: IEEE (Institute of Electrical and Electronics Engineers), 3rd International Conference for Convergence in Technology, I2CT 2018. Pune, India, 6-8 April 2018. IEEE.

Jain, A. and Singh, T., 2019. Security Challenges and Solutions of IoT Ecosystem. Advances in Intelligent Systems and Computing, [e-journal] 933, pp.259-270. DOI: 10.1007/978-981-13-7166-0_25. 
Jia, M., Komeily, A., Wang, Y. and Srinivasan, R.S., 2019. Adopting Internet of Things for the development of smart buildings: A review of enabling technologies and applications. Automation in Construction, [e-journal] 101, pp.111-126. DOI: 10.1016/j.autcon.2019.01.023.

Kim, D. and Kim, S., 2019. Gateway Channel Hopping to Improve Transmission Efficiency in Long-range IoT Networks. KSII Transactions on Internet and Information Systems, [e-journal] 13(3), pp.1599-1610. DOI: 10.3837/tiis.2019.03.027.

Lee, J., Kao, H. and Yang, S., 2014. Service innovation and smart analytics for Industry 4.0 and big data environment. Procedia CIRP, [e-journal] 16, pp.3-8. DOI: 10.1016/j.procir.2014.02.001.

Liu, X., Qin, Z., Gao, Y. and McCann, J.A., 2019. Resource allocation in wireless powered IoT networks. IEEE Internet of Things Journal, [e-journal] 6(3), pp.4935-4945. DOI: 10.1109/JIOT.2019.2895417.

Lombardi, P.L., Giordano, S., Farouh, H. and Yousef, W., 2012. Modelling the smart city performance. Innovation: The European Journal of Social Sciences Research, [e-journal] 25(2), pp.137-149. DOI: 10.1080/13511610.2012.660325.

Maryska, M., Doucek, P., Nedomova, L. and Sladek, P., 2018. The Energy Industry in the Czech Republic: On the Way to the Internet of Things. Economies, [e-journal] 6(2), 13p. DOI: 10.3390/economies6020036.

Maryska, M., Doucek, P., Sladek, P. and Nedomova, L., 2019. Economic Efficiency of the Internet of Things Solution in the Energy Industry: A Very High Voltage Frosting Case Study. Energies, [e-journal] 12(4), 16p. DOI: 10.3390/en12040585.

Minerva, R., Chebudie B.A. and Rotondi, D., 2015. Towards a definition of the Internet of Things (IoT). IEEE Internet Initiative, [online] Available at: $<$ https://www.researchgate.net/publication/317588072_Towards_a_definition_of _the_Internet_of_Things_IoT>[Accessed 29 April 2019].

Moin, S., Karim, A., Safdar, Z., Safdar, K., Ahmed, E. and Imran, M., 2019. Securing IoTs in distributed blockchain: Analysis, requirements and open issues. Future Generation Computer Systems, [e-journal] 100, pp.325-343. DOI: 10.1016/j.future.2019.05.023.

Nouichi, D., Abdelsalam, M., Nasir, Q. and Abbas, S., 2019. IoT Devices Security Using RF Fingerprinting. In: Aconf, Advances in Science and Engineering Technology International Conferences, ASET 2019. Dubai, United Arab Emirates, 26 March-10 April 2019. IEEE.

Panetta, K., 2017. CIOs focused on smart cities should plan infrastructure to support the IoT. Gartner, [online]. 27 March 2017. Available at: <https://www.gartner.com/smarterwithgartner/smart-cities-look-to-the-future> [Accessed 29 April 2019]. 
Perera, C., Liu, C.H., Jayawardena, S. and Chen, M., 2015. A Survey on Internet of Things from Industrial Market Perspective. IEEE Access, [e-journal] 2, pp.1660-1679. DOI: 10.1109/ACCESS.2015.2389854.

Rezanková, H., 2010. Analýza dat z dotazníkových šetření. 2nd ed. Praha: Professional Publishing.

Sittón-Candanedo I., 2019. A New Approach: Edge Computing and Blockchain for Industry 4.0. In: E. Herrera-Viedma, Z. Vale, P. Nielsen, A.M. Del Rey and R.C. Vara, eds, 16th International Conference, Special Sessions. DCAI 2019. Advances in Intelligent Systems and Computing. Springer, Cham. DOI: 10.1007/978-3-030-23946-6_25.

Torre, G., Rad, P. and Choo, K.R., 2019. Implementation of deep packet inspection in smart grids and industrial Internet of Things: Challenges and opportunities. Journal of Network and Computer Applications, [e-journal] 135, pp.32-46. DOI: 10.1016/j.jnca.2019.02.022.

Van Kranenburg, R., 2008. The Internet of Things: A Critique of Ambient Technology and the All-Seeing Network of RFID. Amsterdam, the Netherlands: Institute of Network Cultures.

Venticinque, S. and Amato, A., 2019. A methodology for deployment of IoT application in fog. Journal of Ambient Intelligence and Humanized Computing, [e-journal] 10(5), pp.1955-1976. DOI: 10.1007/s12652-018-0785-4.

\section{ABOUT AUTHORS}

Pavel Sladek - (P.S.) University of Economics in Prague, Czech Republic, Faculty of Informatics and Statistics, Department of Information Technologies, Ph.D. student, e-mail: pavel.sladek@vse.cz, Author's ORCID: 0000-0003-02661737.

Milos Maryska - (M.M.) University of Economics in Prague, Czech Republic, Faculty of Informatics and Statistics, Department of Information Technologies, Assoc. Professor, e-mail: milos.maryska@vse.cz, Author's ORCID: 0000-00032783-4657.

Lea Nedomova - (L.N.) University of Economics in Prague, Czech Republic, Faculty of Informatics and Statistics, Department of System Analysis, Asst. Prof., e-mail: nedomova@vse.cz, Author's ORCID: 0000-0002-8499-959X.

Petr Doucek - (P.D.) University of Economics in Prague, Faculty of Informatics and Statistics, Head of the Department of System Analysis, Prof., e-mail: doucek@vse.cz, Author's ORCID: 0000-0002-5647-661X. 


\section{AUTHOR CONTRIBUTIONS}

P.S. - formal analysis, investigation, data resources; M.M. - conceptualization, methodology, writing original draft; P.D. - writing original draft, paper finalization; L.N. - formal analysis, investigation, final paper preparation, formatting.

\section{CONFLICTS OF INTEREST}

The authors declare no conflict of interest. The funders had no role in the design of the study; in the collection, analyses, or interpretation of data; in the writing of the manuscript, or in the decision to publish the results.

(C) 2020 by the authors. Submitted for possible open access publication under the terms and conditions of the Creative Commons Attribution (CC-BY) license (http://creativecommons.org/licenses/by/4.0/). 